\title{
Infection of human CD4 + rabbit cells with HIV-1: the possibility of the rabbit as a model for HIV-1 infection
}

\author{
Yasuko Yamamura ${ }^{1,6}$, Masaharu Kotani ${ }^{1}$, Md. Iqbal Hossain Chowdhury ${ }^{2}$, \\ Naoki Yamamoto ${ }^{2}$, Kazuhito Yamaguchi ${ }^{3}$, Hajime Karasuyama ${ }^{4}$, \\ Yoshimoto Katsura ${ }^{5}$, and Masayuki Miyasaka ${ }^{1}$ \\ 'Department of Immunology, The Tokyo Metropolitan Institute of Medical Science, Tokyo, Japan \\ 2Department of Microbiology, Tokyo Medical and Dental Unıversity School of Medicıne, Tokyo, Japan \\ IInstitute of Laboratory Animals, Yamaguchi Unıversity School of Medicine, Yamaguchi, Japan \\ ${ }_{4}^{4}$ Basel Institute for Immunology, Basel, Switzerland \\ 5Department of Immunology, Chest Disease Research Institute, Kyoto University, Kyoto, Japan \\ 6Department of Biology, Faculty of Science, Ibaraki University, Ibaraki, Japan
}

Key words syncytia, MOLT-4, p24, AIDS, animal model

\begin{abstract}
Although human $\mathrm{T}$ cell surface glycoprotein CD4 is the cellular receptor for human immunodeficiency virus 1 (HIV-1), the introduction of the human CD4 gene into murine cells does not render them susceptible to HIV-1 infection. Here we have established rabbit transfectant cell lines expressing human CD4 on the cell surface and demonstrated that the CD4 + rabbit transfectants could be readily infected by HIV-1 by co-cultivating with a HIV-1-infected human MOLT-4 T cell line (MOLT-4/HIV). Avid syncytia formation was observed upon co-cultivation and the syncytla abundantly produced HIV-1 mature particles, as revealed by electron microscopy. A significant Increase of HIV-1 p24 antigen was also detected In the culture supernatant. The syncytia formation was blocked by pretreating the transfectant with antl-human CD4 or by pretreating the MOLT-4/HIV with anti-HIV-1 serum obtained from an infected Individual, indicating that the syncytia formed as a result of the Interaction of human CD4 on the rabbit transfectant with the HIV-1 envelope protein expressed on MOLT-4/HIV. In contrast, only a very small proportion of the rabbit transfectants expressed HIV-1-speclfic antigens upon infection with an HIV-1 stock. This may indicate that, although rabbit cells have partially acquired susceptlbility to HIV-1 by transfection of human CD4 gene, rabblt cells may further requlre such a molecule as might be provided by MOLT-4 to become fully susceptlble to HIV-1 infection. The possibility of the rabbit as a model for HIV-1 infection is also discussed.
\end{abstract}

Human immunodeficiency virus 1 (HIV-1) has been shown to be the causative agent of acquired immunodeficiency syndrome (AIDS) In man (1 - 3). Although much information is accumulating on the biology and molecular structure of HIV-1, very little is known about the infection process and Induction mechanisms underlyng AIDS. To develop successtul vaccines and therapeutic regimens for AIDS, an important requirement is a readily available animal model.

Rabbit T cells have been reported to be infectable with a hightitered HIV-1 stock in vitro (4) and in vivo $(5,6)$. Therefore, we considered it likely that cell surface expression of human CD4 renders rabbit T cells highly susceptible to HIV-1 infection and that rabbits introduced with the human $\mathrm{CD} 4$ gene may serve as an important preclinical animal model for AIDS. In this study, we have generated rabbit $T$ cell lines expressing human $\mathrm{CD} 4$ by cDNA transfection and then investigated whether these rabbit transfectants have acquired susceptibility to HIV-1 infection upon expressing human $\mathrm{CD} 4$ on the cell surface.

First, we attempted to introduce human CD4 CDNA into rabbit $\mathrm{T}$ cell lines that had been infected with human $\mathrm{T}$ cell leukemia

Correspondence to: M Mryasaka, Department of Immunology. The Tokyo Metropolitan Institute of Medical Science, 3-18-22, Hon-Komagome, Bunkyo-ku, Tokyo, Japan 113 


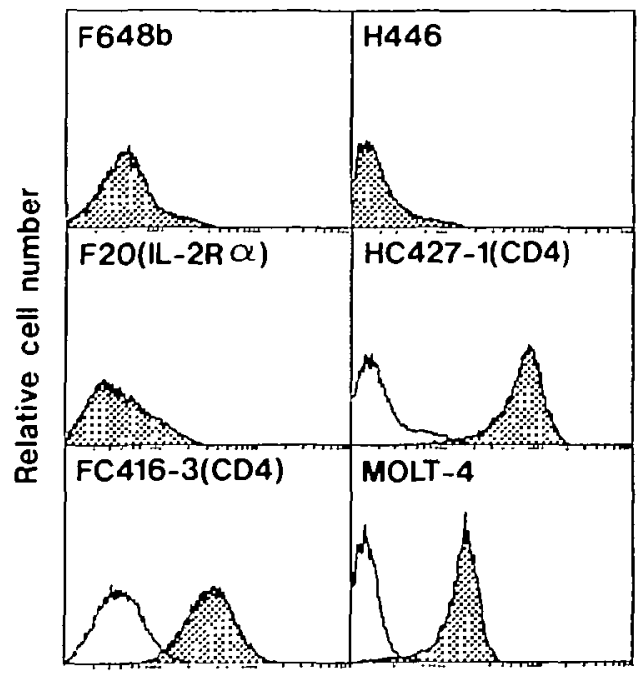

anti-CD4 Fluorescence intensity (log)

Fig. 1. Flow cytometric analysis of human $\mathrm{CD} 4$ expression on rabbit transfectants. Cells were incubated with brotinylated anti-thuman $\mathrm{CD} 4 \mathrm{mAb}$, anti-T4 (Olympus Optical Co. Lid, Tokyo, Japan) for $30 \mathrm{~m} ı$ at $4^{\circ} \mathrm{C}$ and then washed with PBS contaning $0.1 \%$ BSA (Sigma, St Louis, MO) Subsequently cells were incubated with avidin - FITC (Coulter, Hialeah, $\mathrm{FL}$ ) for $30 \mathrm{~min}$ at $4^{\circ} \mathrm{C}$ and washed Cells were analysed by a fuorescence activated cell sorter, EPICS-CS (Coulter).

virus type 1 (HTLV-1). To this end, we subcloned a full-length cDNA encoding human CD4 (7) into the expression vector BCMGSNeo (8), which contains the human cytomegalovirus promoter/enhancer and the bovine papiloma virus (BPV) 69\% fragment (9) to construct BCMGSNeo-hCD4. The BCMGSNeohCD4 was then introduced into the HTLV-1-positive rabbit T cell lines, F648b (10) and H446 (11), and G418-resistant transfectant clones were isolated. Each clone was examined for the expression of human CD4 on the cell surface by the use of a biotinylated anti-human CD4 monoclonal antibody. The isolated transfectant clones, FC416-3 (F648b-derived) and HC427-1 (H446-derived), stably expressed human CD4 and their expression levels were at least several times higher than that of the human T cell line MOLT-4 as assessed by flow cytometry (Fig. 1). In line with this, Scatchard plot analysis using 125. labeled Fab' fragments of anti-human CD4 monoclonal antibody, which recognizes an HIV-1 binding epitope of human CD4, revealed that $\mathrm{HC} 427-1$ and $\mathrm{FC} 416-3$ expressed 370,000 and 56,000 sites/cell of human CD4 respectively, whereas MOLT-4 expressed 13,000 sites/cell (not shown).

We then asked whether the expression of human CD4 on the cell surface rendered these rabbit T cell lines susceptible to HIV-1 infection. First, we examined the ability of these transfectants to support syncytia formation. It has been shown that syncytia form upon co-cultivating human CD4 + cells with HIV-1-infected cells and that this represents a critical cellular process leading to the intracellular replication and extracellular release of HIV-1 particles $(12$ - 14). Whereas nether a parental cell line F648b nor a control cell line F20 transfected with the same expression vector but containing a control cDNA formed syncytia following cocultivation with MOLT-4 which had been infected with HIV-1 (MOLT-4/HIV) (15), human CD4 + transfectant FC416-3 vigorously formed syncytia with MOLT-4/HIV after $24 \mathrm{~h}$ of coculture (Fig. $2 \mathrm{a}-\mathrm{c}$ and Table 1). This heterocellular interaction was completely abrogated by pretreating either FC416-3 cells with anti-human CD4 monocional antibody (OKT4A) or MOLT-4/HIV cells with polyclonal anti-HIV-1 serum from an infected individual (not shown), indicating that the syncytia formation was due to the interaction between human CD4 expressed on rabbit cells and HIV-1 envelope protein expressed on MOLT-4/HIV.

When these syncyta were examined by electron microscopy, extracellular virions with morphology typical of HIV-1 (16) were found abundantly (Fig. 2d and e). Moreover, the notion that HIV-1 replication was actively occurring in the syncytia was further substantiated by the increase of HIV-1 p24 antigen in the culture supernatant (Table 1). The culture supernatant of FC416-3 co-cultured with MOLT-4/HIV contained a much higher level of HIV-1 capsid protein p24 than either the culture supernatant obtained from F648b or F20 co-cultured with MOLT-4/HIV, or that of MOLT-4/HIV. Furthermore, preliminary experiments indicated that the culture supernatant of $\mathrm{FC} 416-3$ forming syncytia was able to transmit HIV-1 into the indicator cell line MOLT-4 (not shown). These results together show that infectious wild-type HIV-1 virions actually replicated in the syncytia and were released extracellularly. The same treatment of murine lymphoma EL-4 that had been transfected with human CD4 resulted in no syncytia formation at all (not shown).

To further assess the susceptubility to HIV-1 infection of the rabbit transfectants expressing human CD4, we inoculated the human $\mathrm{CD} 4$ + rabbit transfectants with cell-free HIV-1 virus particles (HTLV-IIIB) at a multiplicity of infection of 0.5 . The rabbit transfectant clones (FC416-3 and $\mathrm{HC} 427-1$ ) as well as the parental cell lines (F648b and H446) and a control rabbit cell line (F20) were examined by an immunofluorescence assay for the cell surface expression of HIV-1-specific antigens following the HIV-1 inoculation (Table 2). Although all of the control cell lines, including the parental and mock-transfected lines, remaned negative for expression of HIV-1 antigens throughout the course of examınation, small but significant proportions $(0.5-1.0 \%)$ of the transfectants expressing human CD4 became strongly positive for the HIV-1 antigens subsequent to the infection. Comparable results were obtained by the use of anti-gp $120 \mathrm{mAb}$ $0.5 \beta$ (not shown). While previous study by others has shown that the rabbit $T$ cell line, H446, is susceptibe to HIV-1 infection (4), we detected no HIV-1 antigens on $\mathrm{H} 446$ cells after the inoculation with HIV-1. The viral antigen expression was stable in HC427-1 and easily detectable even at day 20 postinfection, whereas in FC416-3 the antigen expression was transient and became negative at day 9 . Atthough $\mathrm{HC} 427-1$ expressed several tımes more human CD4 than FC416-3 (not shown), it remains to be determined whether this could account for the apparent difference in the sensitivity to HIV-1 infection. It has been demonstrated in man that surface expression levels of CD4 do not necessarily correlate with sensitivity of these cells to HIV-1 infection $(17,18)$. The apparent lack of susceptibility of $H 446$ and the relatively low percentages of infected cells in the transfectants remain to be resolved, but it may possibly be due to a lower titer of HIV-1 stock used for the cell-free infection in the present study. Alternatively, rabbit T cells expressing human CD4 may further require such a molecule as might be provided by MOLT-4 to become readily infected with HIV-1. For instance, it has been 


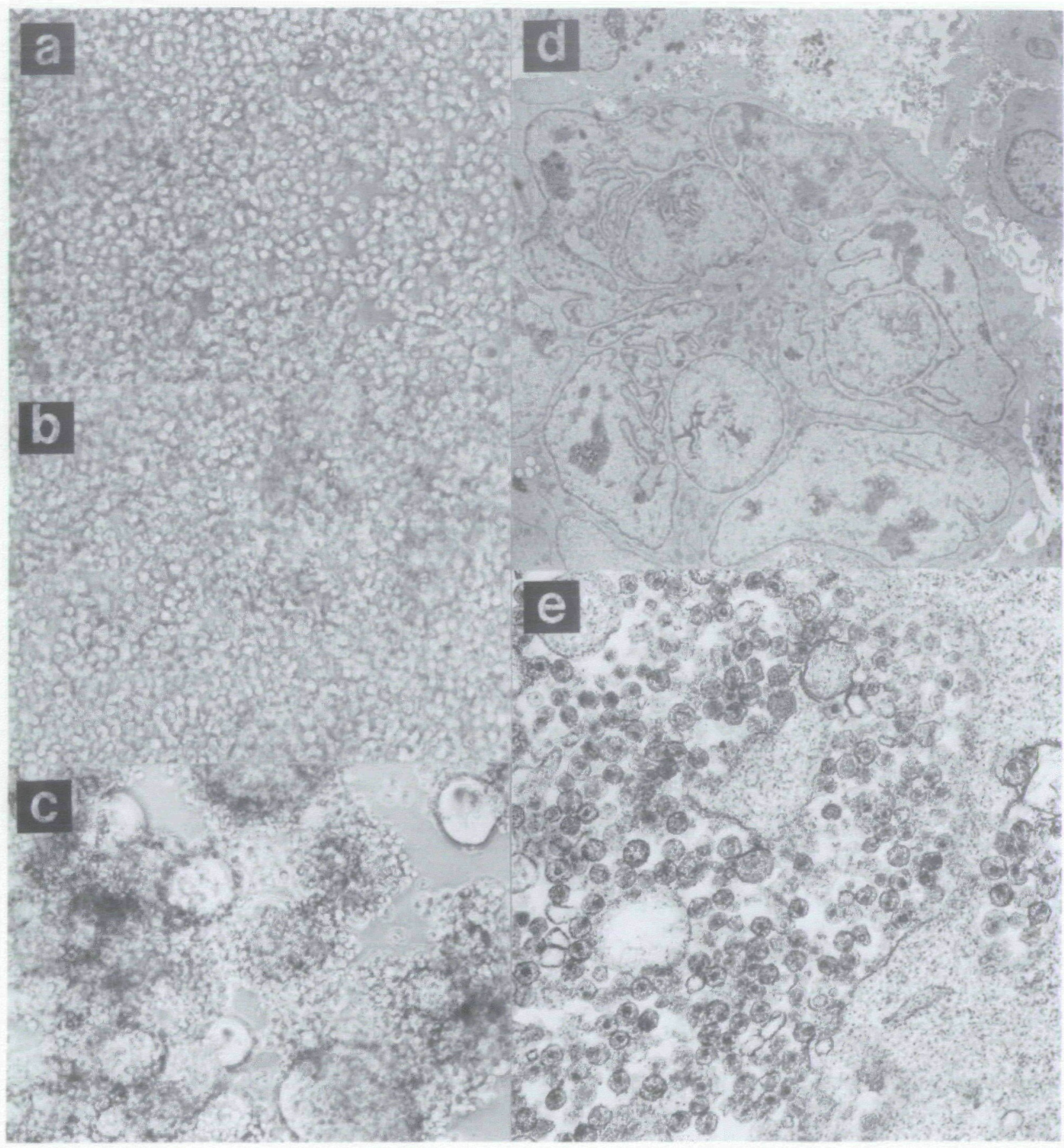

Flg. 2. Human CD4-dependent syncytia formation of rabbyt transfectants with MOLT-4/HIV. $3 \times 105$ rabbit cells were incubated with $3 \times 10^{5}$ MOLT-4/HIV cells in a well of 24 -well plates at $37^{\circ} \mathrm{C}$. After $24 \mathrm{~h}$, cultures were photographed at $\times 100$ magnification. When the rabbit parental cell line F648b (a) or a rabbit transfectant expressing human IL-2 receptor $\alpha$-chain (b) was co-cultured with MOLT-4/HIV, no syncytia formation was found. In contrast, when human CD4 + rabbit transfectant FC416-3 was co-cultured with MOLT-4/HIV, prominent syncytia formation was observed (c). Electron micrograph $(X 3400)$ (d) and $(X 43,000)(e)$ of the syncytium. Many extracellular mature virions with conical core characteristic of HIV-1 were visualized.

reported that trans-acting cellular factors critical for Rev function are present in human but not in murine cells, which may be partly responsible for the narrow HIV-1 tropism (19). Clearly further study is required to resolve this issue.
Although generation of anımal models for HIV. 1 infection is critical in devising therapeutic means for AIDS, attempts to produce mouse models for HIV-1 infection have met with difficulties. Transgenic mice expressing human CD4 do not 
Table 1. Induction of syncytia formation and supernatant p24 activity by co-culturing a human $C D 4+$ rabbit transfectant with HIV-1-infected MOLT-4 (MOLT-4/HIV)

\begin{tabular}{lcc}
\hline Cell lines & $\begin{array}{c}\text { No of } \\
\text { syncytia }\end{array}$ & p24 (ng/ml) \\
\hline F648b & 1 & 57.3 \\
F20 (hlL-2R $\left.\alpha^{+}\right)$ & 0 & 55.8 \\
FC416-3 (hCD $\left.4^{+}\right)$ & 33 & 120.4 \\
MOLT-4/HIV & 0 & 69.8 \\
\hline
\end{tabular}

$3 \times 10^{5}$ cells were incubated with $3 \times 10^{5} \mathrm{MOLT}-4 / \mathrm{HIV}$ cells in a well of 24-well plate at $37^{\circ} \mathrm{C}$. After $24 \mathrm{~h}$ the number of syncyta per vewield was counted under an inverted phase contrast microscope. Simultaneously the culture supernatants were harvested and filtered through a $0.45 \mu \mathrm{m}$ filter and HIV-1 p24 antigen activity was measured by using an HIV p24 antigen ELISA (Abbott Laboratories, North Chicago, IL)

Table 2. Expression of HIV-1-specific antigens on human CD4+ rabbit transfectants after inoculation with HIV-1

\begin{tabular}{lllllllll}
\hline Cell lines & \multicolumn{7}{l}{ Days after infection } \\
\cline { 2 - 8 } & 3 & 5 & 7 & 9 & 11 & 13 & 16 & 20 \\
\hline F648b & - & - & - & - & - & - & - & - \\
F20 (hlL-2R $\left.\alpha^{+}\right)$ & - & - & - & - & - & - & - & - \\
FC416-3 $\left(\mathrm{hCD} 4^{+}\right)$ & + & + & + & - & - & - & - & - \\
H446 & - & - & - & - & - & - & - & - \\
HC427-1 $(\mathrm{hCD} 4+)$ & + & + & + & + & + & + & + & + \\
\hline
\end{tabular}

Infection of cells with HIV-1 was made at a multiplicity of infection of 0.5 at $37^{\circ} \mathrm{C}$ for $1 \mathrm{~h}$. After adsorption of HIV -1 , the cells were washed twice with RPMI 1640, resuspended in RPMI 1640 medum supplemented with $10 \%$ fetal bovine serum (General Scientfic Laboratories, Los Angeles, CA) at a concentration of $4 \times 10^{5} \mathrm{cell} / \mathrm{s} / \mathrm{ml}$, and then incubated at $37^{\circ} \mathrm{C}$. The cells were taken from the cultures at indicated times, smeared on microscope slides, air-dried, and fixed with methanol. Fixed slides were incubated with 1:1,000 diluted anti-HIV-1 serum from an AIDS patient at $37^{\circ} \mathrm{C}$ for $30 \mathrm{~min}$ and then washed with PBS. Subsequently the stides were incubated with fluorescein isothıocyanate (FITC)-conjugated anthuman IgG (Dakopatts A/S, Copenhagen, Denmark) at $37^{\circ} \mathrm{C}$ for $30 \mathrm{~m} ı n$ and then washed with PBS. Cells were examined under a fluorescence microscope.,$+ 0.5-1.096$ of cells are HIV-1-specific antigen positive, - , antigen negatıve.

appear to support the replication of HIV-1 (S. Aizawa and M. Taniguchi, personal communication). Furthermore, mice producing infectious HIV particles in their tissues as a result of introduction of HIV proviral DNA into the germline develop no AIDS disease symptoms (20). Severe combined immunodeficient (SCID) mice grafted with human cells have been shown to support the HIV-1 replication (21), but our preliminary results indicate that production of such reconstituted mice involves considerable technical difficulties. In contrast, previous studies have shown that rabbit cells allow HIV-1 virus to replicate in vitro (4) and in vivo $(5,6)$, although not as efficiently as do human cells. No AIDS-like immunodeficiency has been observed in the HIV-1 infected rabbits. In the present study, we demonstrated that rabbit transfectant cell lines could be readily infected by HIV-1 by co-cultivation with HIV-1 infected human cells. Although low susceptibility of these transfectants to a HIV virus stock may well be a limiting factor, it would still be interesting to examine whether adminıstration of large numbers of HIV-1-infected human cells Into CD4 transgenic rabbits will produce any significant disease symptoms and we are currently attempting to produce such animals.

\section{Acknowledgements}

We thank Dr R. Axel (Columbia University) for the plasmıd T4-pMV7. Dr K. Arau (Tokyo University Schoot of Medicine) for the plasmıd pcDCD4, and Dr A Seto (Shiga University of Medical Science) for the rabbit $T$ cell lines, F648b and H446. This work was supported in part by a grant from the Ministry of Heatth and Welfare and also a grant from the Scrence and Technology Agency, Japan.

\section{Abbrevlatlons}

AIDS

BPV

HIV-1

HTLV-1

acquired immunodeficiency syndrome

bovne papilloma virus

human immunodeficiency virus 1

SCID mouse

human $T$ cell leukemia virus type 1

severe combined immunodeficient mouse

\section{References}

1 Barre-Sinoussi, F., Chermann, J. C., Rey, F., Nugeyre, M T., Chamaret, S., Gruest, J., Dauguet, C., Axder-Błın, C , Vézinet-Brun, F., Rouzioux, C, Rozenbaum, W, and Montagnier, L. 1983 Isotation of a T-lymphotropic retrovirus from a patient at risk for acquired Immune deficiency syndrome (AIDS). Science 220:868.

2 Gallo, R. C, Salahuddın, S Z., Popovic. M. Shearer, G M. Kaplan, M., Haynes, B F, Palker, T. J., Redfield, R., Oleske, J., Safal, B., White, G , Foster, P , and Markham, P. D. 1984. Frequent detection and isolation of cytopathic retroviruses (HTLV-III) from patients with AIDS and at risk for AIDS Science 224:500.

3 Levy, J A, Hoffman, A. D., Kramer, S. M., Landis, J A., Shimabukuro, J M , and Oshiro, L S. 1984. Isolation of lymphocytopathic retroviruses from San Francisco pattents with AIDS. Science 225.840.

4 Kulaga, H., Folks, T. M., Ruttedge, R., and Kındt, T. J. 1988. Infection of rabbit T-cell and macrophage lines with human immunodeficiency virus. Proc. Natl Acad. Sci. USA 85:4455

5 Filice, G., Cereda,P. M., and Varnier, O.E 1988 Infection of rabbits with human immunodeficiency virus. Nature 335.366

6 Kulaga, H., Folks, T, Rutledge, R., Truckenmiller, M. E., Gugel, E. and Kindt, T.J. 1989 Infection of rabbits with human immuno deficiency virus 1. J Exp. Mod. 169:321.

7 Maddon, P. J., Dalgleish, A G., McDougal, J S., Clapham, P. R., Weiss, R. A., and Axel, R. 1986. The T4 gene encodes the AIDS virus receptor and is expressed in the immune system and the brain Cell 47:333.

8 Karasuyama, H., Kudo, A., and Melchers, F. 1990 The protens encoded by the $V_{\text {preB }}$ and $\lambda_{5}$ pre-B cefl-specific genes can associate with each other and with $\mu$ heavy chain J. Exp Med. 172:969

9 Lowy, D. R., Dvoretzky, I., Shober, R., Law, M.F., Engel, L., and Howley, P. M. 1980. In vitro tumorigenic transformation by a defined sub-genomic fragment of bovine papilloma virus DNA. Nature 287.72 .

10 Seto, A., Kawanishi, M., Matsuda, S., Ogawa, K., Eguchı, T., and Miyoshi, I. 1987. Induction of preleukemic stage of adult $T$ cell leukemia-like disease in rabbits. Jpn. J. Cancer Res (Gann) 78.1150.

11 Seto, A., Kawanishi, M., Matsuda, S, and Ogawa, K. 1988 Seronegative virus carriers in the infection of rabbits with human $T$ lymphotropic virus type I. J. Exp. Med. 168:2409.

12 Lifson, J. D., Reyes, G. R, McGrath, M. S , Stein, B. S., and Engleman. E. G. 1986. AID retrovirus induced cytopathology: giant cell formation and involvement of CD4 antigen. Science 232:1123.

13 Lifson, J. D., Feinberg, M B., Reyes, G. R., Rabin, L., Banapour, B., Chakrabarti, S., Moss, B., Wong-Staal, F., Steimer, K. S., and Engleman, E. G. 1986 Induction of CD4-dependent cell fusion by 
the HTLV-III/LAV envetope glycoprotein. Nature 323.725.

14 Sodrosk, J., Goh, W. C., Rosen, C., Campbell, K., and Hasettine, W. A. 1986. Role of the HTLV-IllLAV envetope in syncytium formation and cytopathicity. Nature 322.470.

15 Koyanagi, Y., Harada, S., Takahashi, M., Uchino, F., and Yamamoto, N. 1985. Selective cytotoxicity of AIDS virus infection towards HTLV-I-transformed cell lines. Int. J. Cancer 36:445.

16 Gelderblom, H. R., Hausmann, E H. S., Dezet, M., Pauli, G., and Koch, M. A. 1987. Fine structure of human immunodeficiency virus (HIV) and immunotocalization of structural protens. Virotogy 156:171.

17 Chaffee, S , Leeds, J. M., Matthews, T J., Weinthold, K. J , Skinner, M., Bolognesi, D. P., and Hershfield, M. S. 1988. Phenotypic variation In the response to the human immunodeficiency virus among dervatives of the CEM T and WIL-2 B cell lines. J. Exp Med 168.605. 18 Hillman, K., Shapira-Nahor, O., Gruber, M. F., Hooley, J.,
Manischewitz, J., Seeman, R., Vujcic, L., Geyer, S. J., and Golding, H. 1990. Chemically induced CD4 mutants of a human T cenl line. Evidence for dissociation between binding of HIV I envelope and susceptibility to HIV I infection and syncytia formation. J. Immunol $144 \cdot 2131$

19 Trono, D. and Baltimore, D. 1990. A human cell factor is essential for HIV-1 Rev action. EMBO J. 9:4155.

20 Leonard, J. M., Abramczuk, J. W., Pezen, D. S., Rutledge, R., Betcher, J. H., Hakim, F., Shearer, G., Lamperth, L., Travis, W., Frednckson, T., Notkuns, A L., and Martin, M. A. 1988. Development of disease and virus recovery in transgenic mice containung HIV proviral DNA. Science 242:1665.

21 Namikawa, R., Kaneshima, H., Lieberman, M., Wessman, I. L., and McCune, J. M. 1988. Infection of the SCID-hu mouse by HIV-1. Science 242:1684. 
